\title{
Androgen Receptor Gene Tagging Single Nucleotide Polymorphisms are not Associated with Polycystic Ovary Syndrome in South Indian Women
}

\author{
Himavanth Reddy Kambalachenu ${ }^{1}$, Solomon Franklin Durairaj Paul ${ }^{1,2}$, Sanjeeva \\ Reddy Nellepalli ${ }^{3}$, Perumal Venkatachalam ${ }^{2 *}$ \\ ${ }^{I}$ Department of Biomedical Sciences, Sri Ramachandra University, Chennai, India \\ ${ }^{2}$ Department of Human Genetics, Sri Ramachandra University, Chennai, India \\ ${ }^{3}$ Department of Reproductive Medicine, Sri Ramachandra University, Chennai, India
}

\begin{abstract}
Impaired steroidogenesis at gonads or defect in the receptors mediating the actions of those hormones is being reported as an etiological factor for Polycystic ovary syndrome (PCOS). Of the various factors, variations in the expression of androgen receptor (AR) gene have been shown as a risk factor for women with PCOS; however the findings were not consistent among populations studied. Therefore, the present study was aimed to screen the prevalence of AR gene haplotype tagging single nucleotide polymorphisms (SNP) and its association with PCOS in south Indian women. The study population consists of a total of 198 subjects, of which 97 were women with PCOS and 101 healthy women as controls. Genotyping of SNPs for AR rs5919393 $(C / T), r s 5919411(A / G)$ and $r s 12014709(G / T)$ were carried out by polymerase chain reaction $(P C R)$, restriction fragment length polymorphism (RFLP) and DNA sequencing. Out of three SNPs examined, the rs5919393 (C/T) and rs5919411 (A/G) are monomorphic in both PCOS and controls. Whereas, rs12014709 (G/T) was observed $<2 \%$ in controls samples in the present study. The results did not show any evidence of association of polymorphisms rs5919393 (C/T), rs5919411 (A/G) and rs12014709 (G/T) in AR gene with PCOS in south Indian women.
\end{abstract}

Keywords: Androgen Receptor, Hyperandrogenism, PCOS, SNP.

\section{Introduction}

Polycystic ovary syndrome (PCOS) is an endocrine associated female infertility disorder affecting 6$8 \%$ of women in their reproductive ages [1]. Either a defect in the secretions of hormone or its receptor or any variations in their gene expressions have been reported as an etiological factors in many of those cases. Hyperandrogenism and ovulatory dysfunctions have been observed as common features of PCOS, frequently associated with imbalanced metabolic pathways (insulin resistance, abnormal glucose metabolism), elevated levels of testosterone and luteinizing hormone [2]. Even though the PCOS is one of an extensively studied female infertility disorder, in terms of the biochemical pathways, genetic component is not yet reported in detail [3].

Androgen receptor (AR), a member of nuclear receptor superfamily, mediates the cellular actions of androgens. $A R$ exon $1 \mathrm{CAG}(\mathrm{n})$ repeat polymorphism has been widely studied in androgen associated disorders. Length of CAG(n) repeat had been shown as inversely proportional to $A R$ transcriptional activity [4]. Thus, in short $\operatorname{CAG}(\mathrm{n})$ repeats are associated with excess ovarian androgen production and increased clinical signs of hyperandrogenism, acne vulgaris and serum testosterone levels [5]. In contrast, larger CAG(n) repeats are associated with abnormal spermatogenesis and male infertility [6]. While few studies reported short CAG(n) repeats have been associated with PCOS in Chinese [7] and USA populations [8], Asian and European lineage did not found any association [9, 10]. Furthermore, systematic and meta-analysis of $A R$ CAG(n) repeats data showed an association of testosterone levels in women with PCOS [11]. Association studies of PCOS with (CAG)n repeats have been inconsistent and ethnicity and selection for PCOS may have a major impact in conflict results. In contrast to the CAG repeats, one study on Chinese women with PCOS was found to be associated with $A R$ Exon 1 synonymous SNP rs6152 (G/A) [12].

In the present study we studied the association of $A R$ gene haplotype tagging SNPs with PCOS in South Indian woman. We selected haplotype tag SNPs rs5919393 (C/T), rs5919411 (A/G) and rs12014709 $(\mathrm{G} / \mathrm{T})$ located in intron 1, intron 2 and intron 5 respectively of AR gene.

\subsection{Setting and study design}

\section{Materials And Methods}

The present genetic case control study was approved by Institutional ethics committee (Ref. No: IECNI/08/Aug/05/32) and conducted at SMART clinic, Department of Reproductive Medicine, Sri Ramachandra 
University. Written informed consent was obtained from all the study participants. Blood samples were collected from women with PCOS ( $\mathrm{n}=97$ ), who follows the 2003, Rotterdam diagnostic criteria for PCOS, showing any two of the following conditions: clinical or biochemical signs of hyperandrogenism, oligo and/or anovulation and presence of polycystic ovaries with ultra sound scan. Further, the study subjects were excluded if they have any signs of other related etiologies such as endometriosis, thyroid disorders, congenital adrenal hyperplasia, hyperprolactinemia [13]. Healthy subjects $(n=101)$ were recruited from unrelated general population showing no history of infertility, clinical signs of hyperandrogenism and anovulation.

\subsection{Haplotype Tag SNPs (htSNPs) selection}

The $A R$ htSNPs were selected based on the International hapmap data available for Gujarathi Indians in Houston (GIH) population. We used web based SNPinfo LD TAG SNP bioinformatics tool [14] (http://snpinfo.niehs.nih.gov/snpinfo/snptag.htm) to select the htSNPs using GIH hapmap data for $A R$ gene by pairwise tagging and $\mathrm{r}^{2}$ of 0.8 and minor allele frequency in the range of $0.05-0.5$.

\subsection{Genotyping of $A R$ htSNPs}

Genomic DNA was extracted from whole blood using standard phenol chloroform method [15]. Genotyping was carried out by PCR-RFLP for rs5919393 (C/T) and rs5919411 (A/G) and by direct sequencing of PCR products generated for rs12014709 (G/T). All the PCR reactions was carried out in 20uL reaction containing 10ul of 2X PCR master mix (Ampliqon, Dutch), 20 picomoles of forward and reverse primers each and 5.6uL of Nuclease free water and 50ng of genomic DNA. PCR cycling conditions were for initial denaturation at $95^{\circ} \mathrm{C}$ for 5 minutes, followed by 34 cycles at $95^{\circ} \mathrm{C}$ for 1 minute each; annealing of primers was at $63.4^{\circ} \mathrm{C}$ (for rs5919393), $64.8^{\circ} \mathrm{C}$ (for rs5919411) and $61.2^{\circ} \mathrm{C}$ (for rs 12014709 ) for 35 seconds and extension for $72^{\circ} \mathrm{C}$ for 60 seconds respectively and single step of final extension at $72^{\circ} \mathrm{C}$ for 7 minutes. Primer sequences and PCR product size were provided in Table 1. Amplified PCR products of rs5919393 (C/T) were subjected to restriction digestion by $\mathrm{XcmI}$ (New England Bio) for $\mathrm{C} / \mathrm{C}$ genotype give three products 262, 248, 89 bp size, $\mathrm{C} / \mathrm{T}$ will give four bands of $337,262,248,89 \mathrm{bp}$ and T/T will yield in to two bands of 337 and $262 \mathrm{bp}$ in size. Restriction digestion of rs5919411 (A/G) with AjuI (Fermentas) give three bands of 316, 245 and 32bp for A/A genotype, four bands of 593, 316, 245 and 32bp size and single band without digestion of 593bp size for G/G. Few samples were subjected to DNA sequencing for confirmation of RFLP results. SNP rs12014709 (G/T) PCR products were subjected to direct DNA sequencing by using standard BigDyeTM cycle sequencing protocol and analyzed by Applied Biosystem 3730 DNA analyzer.

Table 1. PCR primers, product size (bp) and methodology for $A R$ gene htSNPs

\begin{tabular}{|c|c|c|c|c|}
\hline SNP & Primer & $\begin{array}{l}\text { Size } \\
\text { (bp) }\end{array}$ & Method & Reference \\
\hline \multirow{2}{*}{ rs5919393 (C/T) } & ATGATCTGGAGCTGGTTAAGTGAAGTC & \multirow{2}{*}{599} & \multirow{2}{*}{ PCR-RFLP } & \multirow{2}{*}{ This study } \\
\hline & $\begin{array}{l}\text { ACAAAATATTATATGCCCATTTTGAGGC } \\
\end{array}$ & & & \\
\hline \multirow{2}{*}{ rs5919411 (A/G) } & TTTGTAGCCCTACACCAAACACACCTTT & \multirow{2}{*}{593} & \multirow{2}{*}{ PCR-RFLP } & \multirow{2}{*}{ This study } \\
\hline & TGCTGTGCCAGACTTCTGACTTACAAAA & & & \\
\hline \multirow{2}{*}{ rs12014709 (G/T) } & CTAGTGCCTGTTGGAGACAAGAT & \multirow{2}{*}{850} & \multirow{2}{*}{ PCR - Sequencing } & \multirow{2}{*}{ This study } \\
\hline & GAAGGTCAATTCCTGTCCTGACT & & & \\
\hline
\end{tabular}

\section{Statistics}

Allele frequencies and geneotype count for $A R$ htSNPs were calculated using plink software[16].

\section{Results}

The age of groups is $26.20 \pm 4.12$ (Mean \pm SD) in PCOS and $26.11 \pm 4.10$ (Mean \pm SD) in control subjects. The allele and genotype frequency obtained for the three SNPs for the PCOS and control subjects are given in Table 2. PCR amplification of rs5919393 and rs5919411 yield a product size of single band of 599bp and 593bp respectively. All the samples subjected to restriction digestion for SNP rs5919393 (C/T) with XcmI enzyme produced two bands, indicating the study subjects has only homozygous wild (T/T) genotype and complete absence of heterozygous (T/C) and homozygous variant $(\mathrm{C} / \mathrm{C})$ genotypes (Table 2). Similarly, the SNP rs5919411 (A/G), subjected to restriction digestion with AjuI also shows only G/G genotype and without any presence of G/A or A/A genotype (Table 2). The genotype results obtained with RFLP were further confirmed by DNA sequencing of randomly selected samples (Fig 1 A and B). The third SNP rs12014709 (G/T) was analyzed by direct sequencing of PCR products of which $<2 \%$ of control samples were found be heterozygous and remaining were homozygous wild (T/T) (Table 2) (Fig $1 \mathrm{C}$ and D). 


\section{Discussion}

Clinical phenotypes like hyperandrogenism and ovulatory dysfunctions have been observed as common features of PCOS. In parallel an imbalanced metabolic pathways (insulin resistance, abnormal glucose metabolism), elevated levels of testosterone and luteinizing hormone had been associated with PCOS [2]. In women with PCOS, hypersecretion of LH in pituitary, stimulates the androgen production in ovarian theca cells, whereas, relative low levels of FSH failed to induce aromatization of androgens into estrogens in granulosa cells $[17,18,19]$. AR expressed on ovarian granulosa cells in several mammalian species, most abundantly in pre- and early antral ovarian follicles and gradually declined upon maturation of the ovarian follicle [20]. Recent studies on both human and animals models underlines the importance of AR in follicle growth and survival, FSH mediated dominant follicle selection and conversion of androgens to estrogens in granulosa cell and its impact on its altered expressions [21, 22]. Differential expressions of AR at different stages of folliculogenesis, implies the essential role of this receptor on normal functions of ovary. $A R$ gene knockout mice studies, provided information related to defective regulation of pituitary gonadotropins and ovulation leading to subfertility [23].

Table 2. AR gene htSNP allele frequencies and genotype distribution in PCOS and Controls

\begin{tabular}{|c|c|c|c|c|c|c|}
\hline SNP & Subjects & Minor allele & Major allele & \multicolumn{3}{|c|}{ Genotype(n) } \\
\hline \multirow{2}{*}{ rs5919393 (C/T) } & PCOS & C: 0.00 & T: 1.00 & C/C: 00 & C/T: 00 & T/T: 97 \\
\cline { 2 - 7 } & Controls & C: 0.00 & T: 1.00 & C/C: 00 & C/T: 00 & T/T: 101 \\
\hline \multirow{2}{*}{ rs5919411 (A/G) } & PCOS & A: 0.00 & G: 1.00 & A/A: 00 & A/G: 00 & G/G: 97 \\
\cline { 2 - 8 } & Controls & A: 0.00 & G: 1.00 & A/A: 00 & A/G: 00 & G/G: 101 \\
\hline \multirow{2}{*}{ rs12014709 (G/T) } & PCOS & G: 0.00 & T: 1.00 & G/G: 00 & G/T: 00 & T/T: 97 \\
\cline { 2 - 7 } & Controls & G: 0.02 & T: 0.98 & G/G: 00 & G/T: 02 & T/T: 99 \\
\hline
\end{tabular}

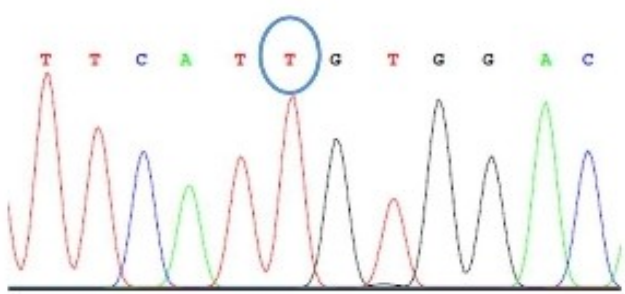

A

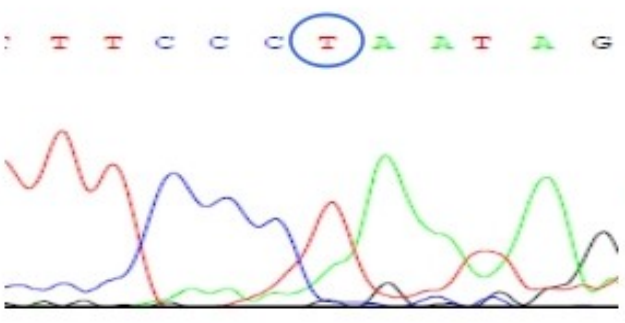

$\mathrm{C}$

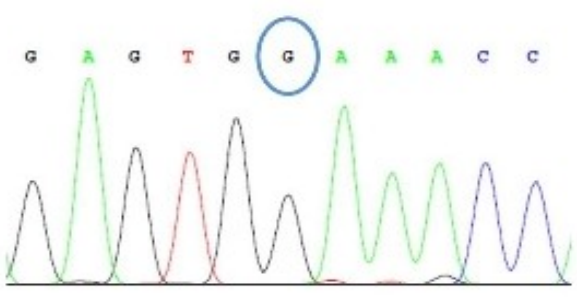

B

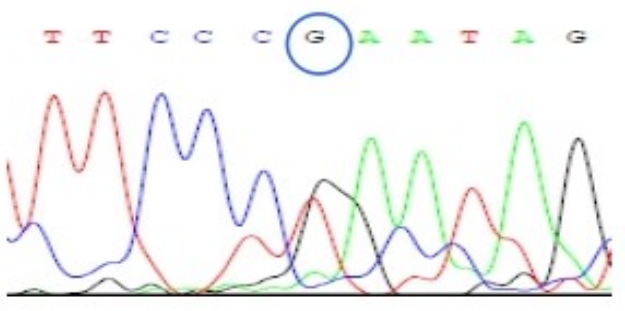

D

Figure 1. $A R$ gene SNP genotype confirmation by DNA sequencing; (A): rs5919393 (T/T) genotype; (B): rs5919411 (G/G) genotype; (C): rs12014709 (T/T) genotype and (D) rs12014709 (G/T) genotype with heterozygous double peak.

In the present study we tested the association of $A R$ gene htSNPs rs5919393 (C/T), rs5919411 (A/G) and rs12014709 (G/T) in women with PCOS. Our study did not found any significant association of $A R$ gene htSNPs with PCOS. SNP rs5919393 and rs5919411 are monomorphic in the present study and rs12014709 $(\mathrm{G} / \mathrm{T})$ is absent in PCOS and less prevalent $(<2 \%)$ in control subjects (Table 2). RFLP analysis of rs5919393 $(\mathrm{C} / \mathrm{T})$ and $\mathrm{rs} 5919411(\mathrm{~A} / \mathrm{G})$ showed the presence of only wild homozygous $\mathrm{T} / \mathrm{T}$ and $\mathrm{G} / \mathrm{G}$ genotypes respectively in both PCOS and control subjects. However, for rs12014709 (G/T), showed only T/T genotype in all PCOS samples and controls with exception of two controls samples are heterozygous $(\mathrm{T} / \mathrm{G})$. These results are in comparison with HapMap data for Asian populations like Japanese in Tokyo, Japan (JPT) and Han Chinese in Beijing, China (CHB) and Korean population data obtained from allele frequency database [24]. In contrast to African population like Yoruba in Ibadan, Nigeria (YRI) showed the complete absence of wild homozygous genotype $(\mathrm{T} / \mathrm{T})$ and the presence of wild homozygous $(\mathrm{C} / \mathrm{C})$, but seems to be polymorphic in other African populations like Maasai in Kinyawa, Kenya (MKK) and African ancestry in Southwest USA (ASW) and European population like Utah residents with Northern and Western European ancestry from the CEPH 
collection (CEU). SNP rs5919393 (C/T) found to be associated with endometrial cancer [25], and androgenetic alopecia in European population [26]. However, SNP rs5919393 is found to be monomorphic in Chinese population [27] and in the present study (Table 2). SNP rs5919411 (A/G) reported in prostate cancer [28], and rs12014709 (G/T) in spontaneous preterm birth [29] and Hypospadias [30], but failed to found any significant association.

In conclusion, the present study on $A R$ gene htSNPs rs5919393 (C/T) (T/C), rs59191411 (G/A) and rs12014709 (G/T) (T/G) did not show any significant association with PCOS in South Indian women. These SNPs are rare in South Indian, Japanese, Chinese and Korean populations, but are polymorphic in other populations like African and European ancestry.

\section{Acknowledgements}

Authors acknowledges Indian council of Medical Research (ICMR), India for awarding the Senior Research Fellowship (Ref: 3/12/RHN/SRF/2008) and Dr. Mona Pandurangi, Associate professor, Department of Reproductive medicine; Dr V. Vettriselvi, Assistant Professor, Department of Human Genetics, Sri Ramachandra University, Chennai, India for their clinical and scientific inputs.

\section{References}

[1] R Azziz, E Carmina, D Dewailly, E Diamanti-Kandarakis, HF Escobar-Morreale, W Futterweit, OE Janssen, RS Legro, RJ Norman, AE Taylor, SF Witchel. The Androgen Excess and PCOS Society criteria for the polycystic ovary syndrome: the complete task force report. Fertil Steril. 2009; 91:456-88.

[2] MO Goodarzi, DA Dumesic, G Chazenbalk, R Azziz. Polycystic ovary syndrome: etiology, pathogenesis and diagnosis. Nat Rev Endocrinol. 2011; 7:219-31.

[3] M Simoni, CB Tempfer, B Destenaves, BC Fauser. Functional genetic polymorphisms and female reproductive disorders: part I: polycystic ovary syndrome and ovarian response. Hum Reprod Update. 2008; 14:459-484

[4] I Palazzolo, A Gliozzi, P Rusmini, D Sau, V Crippa, F Simonini, E Onesto, E Bolzoni, A Poletti. The role of the polyglutamine tract in androgen receptor. J Steroid Biochem Mol Biol. 2008; 108:245-53.

[5] L Skrgatic, DP Baldani, JZ Cerne, P Ferk, K Gersak. CAG repeat polymorphism in androgen receptor gene is not directly associated with polycystic ovary syndrome but influences serum testosterone levels. J Steroid Biochem Mol Biol. 2012; 128:107-12.

[6] CA Davis-Dao, ED Tuazon, RZ Sokol, VK Cortessis. Male infertility and variation in CAG repeat length in the androgen receptor gene: a meta-analysis. J Clin Endocrinol Metab. 2007; 92:4319-26

[7] D Tong, J Deng, H Sun, L Chen, X Wu. The relationship between CAG repeat length polymorphism and infertility in Southern Chinese Han women. J Endocrinol Invest. 2010; 33:559-63.

[8] NA Shah, HJ Antoine, M Pall, KD Taylor, R Azziz, MO Goodarzi. Association of androgen receptor CAG repeat polymorphism and polycystic ovary syndrome. J Clin Endocrinol Metab. 2008; 93:1939-45.

[9] P Ferk, MP Perme, N Teran, K Gersak. Androgen receptor gene (CAG)n polymorphism in patients with polycystic ovary syndrome. Fertil Steril. 2008: 90: 860-3.

[10] S Dasgupta, PV Sirisha, K Neelaveni, K Anuradha, AG Reddy, K Thangaraj, BM Reddy. Androgen receptor CAG repeat polymorphism and epigenetic influence among the south Indian women with Polycystic Ovary Syndrome. PLoS One. 2010; 5: e12401.

[11] T Zhang, W Liang, M Fang, J Yu, Y Ni, Z Li. Association of the CAG repeat polymorphisms in androgen receptor gene with polycystic ovary syndrome: a systemic review and meta-analysis. Gene. 2013; 524:161-7

[12] CY Peng, XY Long, GX Lu. Association of AR rs6152G/A gene polymorphism with susceptibility to polycystic ovary syndrome in Chinese women. Reprod Fertil Dev. 2010; 22(5):881-5.

[13] Rotterdam ESHRE/ASRM-Sponsored PCOS consensus workshop group. Revised 2003 consensus on diagnostic criteria and longterm health risks related to polycystic ovary syndrome (PCOS). Hum Reprod. 2004; 19: 41-7

[14] Z Xu, JA Taylor. SNPinfo: integrating GWAS candidate gene information into functional SNP selection for genetic association studies. Nucleic Acids Res. 2009; 37(Web server issue):W600-W605

[15] J Sambrook, EF Fritsch, T Maniatis. Molecular Cloning: A Laboratory Manual (2nd edn. Cold Spring Harbor Laboratory Press, New York, 1989; 9:17-19).

[16] S Purcell, B Neale, K Todd-Brown, L Thomas, MA Ferreira, D Bender, J Maller, P Sklar, PI de Bakker, MJ Daly, PC Sham. PLINK: a tool set for whole-genome association and population-based linkage analyses. Am J Hum Genet. 2007; 81:559-75.

[17] B McCourt, KA Martin, EJ Anderson, JM Adams, D Schoenfeld, JE Hall. Determinants of abnormal gonadotropin secretion in clinically defined women with polycystic ovary syndrome. J Clin Endocrinol Metab. 1997: 82:2248-56.

[18] C Stocco. Aromatase expression in the ovary: hormonal and molecular regulation. Steroids. 2008; 73:473-87.

[19] S Kimura, T Matsumoto, R Matsuyama, H Shiina, T Sato, K Takeyama, S Kato. Androgen receptor function in folliculogenesis and its clinical implication in premature ovarian failure. Trends Endocrinol Metab. 2007; 18:183-9.

[20] S Rice, K Ojha, S Whitehead, H Mason. Stage-specific expression of androgen receptor, follicle-stimulating hormone receptor, and anti-Müllerian hormone type II receptor in single, isolated, human preantral follicles: relevance to polycystic ovaries. J Clin Endocrinol Metab. 2007; 92: 1034-40.

[21] A Sen, SR Hammes. Granulosa cell-specific androgen receptors are critical regulators of ovarian development and function. Mol Endocrinol. 2010; 24:1393-403.

[22] ME Nielsen, IA Rasmussen, SG Kristensen, ST Christensen, K Møllgård, E Wreford Andersen, AG Byskov, C Yding Andersen. In human granulosa cells from small antral follicles, androgen receptor mRNA and androgen levels in follicular fluid correlate with FSH receptor mRNA. Mol Hum Reprod. 2011; 17:63-70.

[23] YC Hu, PH Wang, S Yeh, RS Wang, C Xie, Q Xu, X Zhou, HT Chao, MY Tsai, C Chang. Subfertility and defective folliculogenesis in female mice lacking androgen receptor. Proc Natl Acad Sci U S A. 2004; 101:11209-14.

[24] H Rajeevan, U Soundararajan, JR Kidd, AJ Pakstis, KK Kidd. "ALFRED: an allele frequency resource for research and teaching." Nucleic Acids Research. 2012; 40: D1010-15.

[25] HP Yang, J Gonzalez Bosquet, Q Li, EA Platz, LA Brinton, ME Sherman, JV Lacey Jr, MM Gaudet, LA Burdette, JD Figueroa, JG Ciampa, J Lissowska, B Peplonska, SJ Chanock, M Garcia-Closas. Common genetic variation in the sex hormone metabolic 
pathway and endometrial cancer risk: pathway-based evaluation of candidate genes. Carcinogenesis. 2010; 31:827-33.

[26] AM Hillmer, S Hanneken, S Ritzmann, T Becker, J Freudenberg, FF Brockschmidt, A Flaquer, Y Freudenberg-Hua, RA Jamra, C Metzen, U Heyn, N Schweiger, RC Betz, B Blaumeiser, J Hampe, S Schreiber, TG Schulze, HC Hennies, J Schumacher, P Propping, T Ruzicka, S Cichon, TF Wienker, R Kruse, MM Nothen. Genetic variation in the human androgen receptor gene is the major determinant of common early-onset androgenetic alopecia. Am J Hum Genet. 2005; 77:140-8.

[27] B Liang, C Yang, X Zuo, Y Li, Y Ding, Y Sheng, F Zhou, H Cheng, X Zheng, G Chen, Z Zhu, J Zhu, X Fu, T Wang, Y Dong, D Duan, X Tang, H Tang, J Gao, L Sun, S Yang, X Zhang. Genetic variants at 20 p11 confer risk to androgenetic alopecia in the Chinese Han population. PLoS One. 2013;8(8):e71771.

[28] T Sun, GS Lee, L Werner, M Pomerantz, WK Oh, PW Kantoff, ML Freedman. Inherited Variations in AR, ESR1, and ESR2 Genes Are Not Associated With Prostate Cancer Aggressiveness or With Efficacy of Androgen Deprivation Therapy. Cancer Epidemiol Biomarkers Prev. 2010; 19:1871-8.

[29] Karjalainen MK1, Huusko JM, Ulvila J, Sotkasiira J, Luukkonen A, Teramo K, Plunkett J, Anttila V, Palotie A, Haataja R, Muglia $\mathrm{LJ}$, Hallman M. A potential novel spontaneous preterm birth gene, AR, identified by linkage and association analysis of X chromosomal markers. PLoS One. 2012; 7: e51378.

[30] T Adamovic, HT Thai, A Liedén, A Nordenskjöld. Association of a tagging single nucleotide polymorphism in the androgen receptor gene region with susceptibility to severe hypospadias in a Caucasian population. Sex Dev, 2013;7(4):173-9. 